\title{
FOOT DROP IN LEPROSY
}

by Johs. G. Anidersin, CANI). meid. et. CHIR. (HAFN.)

From Sevapur Hospital and Santipara Leprosy Colony, Assam Author's present address: Purulia Leprosy Home and Hospital,

$$
\text { W. Bengal }
$$

Foot drop is a fairly common disability in leprosy. Its correction is of the greatest importance to the patient's chances of a successful revalidation.

The cause is a paralysis of the lateral popliteal nerve at the popliteal fossa. Two distinct patterns of paralysis are recognised: Complete Lateral Popliteal Paralysis with involvement of all the muscles of the anterior and lateral compartments, and Incomplete Lateral Popliteal Paralysis with involvement only of the anterior compartment. Cases presenting Irregular Patterns of Paralysis with some muscles outside the anterior and the lateral compartment paralysed as well, and Partial Patterns of Paralysis with only some of the muscles of the anterior and/or the lateral compartments paralysed should be very carefully examined to determine whether a concomitant paralysing disease as poliomyelitis is responsible or whether it is a biological variant of the leprosy itself. A large number of the partial patterns of paralysis represent developing paralyses, either progressing or regressing.

We do not at present have any exact data concerning the possible recovery of paralyses due to leprosy. It can however, be stated that a stable paralysis of not less than 6 months duration has no chances of recovery.

Correction of foot drop with spring attachments to the foot wear should be considered a temporary relief. Corrections by surgery on the skeleton of the foot may be possible, but it is much more daring and difficult surgery than tendon transfers and has no place where tendon transfer is possible (HoDGEs, 1956).

Since the tibialis posterior muscle for practical purposes always is intact in leprosy, this is the motor tendon of choice. Several techniques have been described. (FRITSCHI and BRAND 1957, GUNN and Molesworth 1957, Selvapandian and Brand 1959, Andersen, under printing.)

The various methods can be summarised as follows:

(1) Interosseous transfer to the middle cuneiform bone;

(2) Subcutaneous, circumtibial transfer to the middle cuneiform bone;

(3) Interosseous transfer to the anterior compartment muscles high in the leg;

(4) Subcutaneous, circumtibial transfer of tib. post. to the insertion of tib. ant., and retrograde transfer of peroneus longus to tib. post; 
(5) Subcutaneous, circumtibial transfer of tib. post. to the insertion of tib. ant., and retrograde transfer of ext. dig. long. to tib. post.

A comparison between the various methods bring the following points out:

Route: the circumtibial route seems to be slightly better than the interosseous route. This may be due to the occasional, very crippling adhesions in the narrow interosseous space. No troublesome bow stringing has been seen in the circumtibial route.

Tension: Due to the strong action of the triceps surae a certain drop in dorsiflexion can be expected. This indicates the necessity of suturing the transposed tendons under high tension with the foot in dorsiflexion.

Insertion: A certain amount of evidence will be found to indicate that the dreaded disorganisation of the skeleton of the foot (neuropathic foot) begins in the tarsal region. It will be wise to avoid surgical interference with the skeleton in this region.

Postoperative stability of the foot: Transfer in a single tunnel is easier, but requires careful balancing of the foot to avoid postoperative inversion deformities. This does not appear to be unduly difficult. It has been postulated that a two guy rope transfer would tend to stabilise the midtarsal joints. This is a point which only a careful, long time follow up study can clarify.

Presently suggested technique

The tibialis posterior tendon is identified and detached at its insertion. It is withdrawn into an incision on the medial side of the leg, and the distal short fibres are detached from the tendon, which is tunnelled in the strictly subcutaneous layer round the tibial border of the tibia in the direction of the base of the $\mathrm{V}$ metatarsal bone. This is easily done with a curved blunt tendon tunneller as described by the author. The transposed tendon is looped round the ext. hall. longus tendon and is secured to the tendon of the ext. dig. long. The tendon suture is done under high tension with the foot in dorsiflexion. After skin suture the foot is secured in a below-the-knee plaster of Paris boot with incorporated toe guard. After a few days the patient can be ambulated in a walking cast. After 4 weeks the plaster boot is removed and the foot is maintained in a dorsal slab while active physiotherapy is instituted. The majority of patients will achieve a normal gait in 2 to 3 weeks and they can then be discharged with suitable shoes as prevention against ulceration of the foot. The operation lends itself to simultaneous correction of drop or flaw toes. No overaction on the dorsiflexion of toes has been noticed.

Material: All the patients in this series were inmates of Santipara Leprosy Colony, Assam. Patients in need of bone surgery for the correction of gross instability of fixed deformities were excluded. Otherwise the patients were accepted for surgery as and when they were ready. No attempts at selection according to age, sex, classifica- 
tion of leprosy, etc. were made. Practical difficulties irrelevant to this paper prevented any women from being selected. In all cases the duration of the disease and of the paralysis extended over several years. It is the impression of the author that the average age in this series is higher than in the series published from Vellore and Karigiri by the authorities. It could be expected that this would tend to give less satisfactory results. The patients were selected at the leprosy colony by the resident physiotherapist and the author. The pre- and postoperative physiotherapy took place at the colony, while the actual surgery in most cases was performed at Sevapur Hospital. The necessary travei to and from the hospital (in the dry season 50 miles, in the wet season 100 miles) was both a hazard and a difficulty. Type of paralysis: 10 cases showed complete lateral popliteal paralysis, 2 cases showed incomplete lateral popliteal paralysis.

Five patients had only one foot paralysed, while four patients had both feet paralysed. (In one case a different technique was employed on one foot.) No difference can be demonstrated in the final postoperative assessment. In case of bilateral paralysis the patients seem to find it a little harder to overcome the initial insecurity of the operated foot.

Where preoperative passive dorsiflexion of the foot with straight knee did not reach $70^{\circ}$, contracture of the heel cord was diagnosed. This was treated with a frontal $\mathrm{Z}$ plasty of the tendo tricipis surae at the time of operation. If the foot was found unstable either on stance or on passive handling it was excluded, since this was considered an indication for triple arthrodesis. Only in one case (No. IIX) where the patient pleading high age requested tendon transfer without bone surgery, was this done. Much to my surprise no postoperative instability was found.

The postoperative assessment was done not later than 2 months after the actual surgery. The majority of the cases had a follow up period of not less than 12 months.

The pre- and postoperative assessments will be found in Table 1. The figures speak for themselves, but a few comments will be necessary: Case Nos. VII and IIX: in both cases a mild high stepping gait is recorded. Both of these were fairly old. They did achieve a normal gait, but found it too much of an effort to break the long standing habit of high stepping unless they gave their minds to it. Case No. V shows a mild highstepping gait with a comparatively poor active dorsiflexion. He had postoperative fever with swelling of the leg, which necessitated splitting of the cast. He did, however, recognise a substantial improvement.

Relative value of recorded angles

With the knee kept flexed the release angle drops about $10^{\circ}$. This will be the expected active dorsiflexion angle. This would indicate that the foot must be kept at $70^{\circ}$ at tendon suture in order to achieve 
TABLE No. 1

\begin{tabular}{|c|c|c|c|c|c|c|c|c|c|c|c|c|c|c|}
\hline & $\begin{array}{c}\text { Stability } \\
\text { of foot }\end{array}$ & $\mid \begin{array}{c}\text { Passive } \\
\text { dorsiflexion } \\
\text { withflexed } \\
\text { knee }\end{array}$ & $\begin{array}{c}\text { Passive } \\
\text { forsiflexion } \\
\text { with str't } \\
\text { knee }\end{array}$ & $\begin{array}{c}\text { Tendon } \\
\text { suture } \\
\text { angle }\end{array}$ & $\begin{array}{l}\text { Release } \\
\text { angle }\end{array}$ & $\begin{array}{c}\text { Immo- } \\
\text { bilisation } \\
\text { angle }\end{array}$ & \begin{tabular}{|l} 
Tendon \\
Achillis \\
engthening
\end{tabular} & $\begin{array}{l}\text { Angle } \\
\text { gained }\end{array}$ & $\begin{array}{c}\text { Active } \\
\text { postoperative } \\
\text { range with } \\
\text { flexed knee }\end{array}$ & $\begin{array}{c}\text { Active } \\
\text { postoperative } \\
\text { range with } \\
\text { straight knee }\end{array}$ & $\begin{array}{c}\text { Postoperative } \\
\text { gait }\end{array}$ & \begin{tabular}{|}
$\begin{array}{c}\text { Post- } \\
\text { operative. } \\
\text { stability }\end{array}$ \\
sta
\end{tabular} & $\begin{array}{l}\text { Assessment } \\
\text { of result }\end{array}$ & $\begin{array}{l}\text { Patient's } \\
\text { statement }\end{array}$ \\
\hline I & good & - & 70 & 70. & 80. & 80 & - & & $76 / 110$ & $80 / 110$ & normal & good & exc. & good \\
\hline II & good & 56 & 56 & 75 & 80 & 75 & & & $85 / 95$ & $85 / 110$ & normal & good & exc. & good \\
\hline III & good & 65 & 70 & 70 & 80 & 65 & & & $70 / 105$ & $85 / 105$ & normal & good & exc. & good \\
\hline IV & good & 65 & 75 & 70 & 70 & 65 & $10 \mathrm{~mm}$ & $10^{\circ}$ & $70 / 105$ & $85 / 105$ & normal & good & exc. & good \\
\hline V & good & 65 & 70 & 65 & 70 & 65 & & & $80 / 90$ & $80 / 90$ & $\begin{array}{l}\text { high st. } \\
\text { mild }\end{array}$ & good & good & good \\
\hline VI & good & 65 & 70 & 65 & 80 & 65 & & & $75 / 105$ & $80 / 105$ & normal & good & exc. & good \\
\hline VII & good & 60 & 70 & 70 & 85 & 70 & & & $85 / 95$ & $90 / 95$ & $\begin{array}{l}\text { high st. } \\
\text { mild }\end{array}$ & good & good & impr. \\
\hline VIII & defic. & 75 & 80 & 70 & 80 & 65 & $10 \mathrm{~mm}$ & $15^{\circ}$ & $80 / 95$ & $85 / 95$ & $\begin{array}{l}\text { high st. } \\
\text { mild }\end{array}$ & good & good & good \\
\hline IX & good & 65 & 70 & 65 & 75 & 65 & & & $80 / 105$ & $85 / 105$ & normal & good & exc. & good \\
\hline $\mathrm{X}$ & good & 65 & 70 & 70 & 80 & 70 & & & $80 / 105$ & $80 / 105$ & normal & good & exc. & good \\
\hline XI & good & 65 & 75 & 65 & 75 & 70 & & & $80 / 105$ & $85 / 105$ & normal & good & exc. & good \\
\hline $\begin{array}{c}\text { XII } \\
\text { Average }\end{array}$ & good & 60 & 70 & $\begin{array}{l}75 \\
69^{\circ}\end{array}$ & $\begin{array}{l}75 \\
78\end{array}$ & $\begin{array}{l}70 \\
68\end{array}$ & & & $\begin{array}{l}85 / 95 \\
78 /\end{array}$ & $\begin{array}{l}90 / 105 \\
84 /\end{array}$ & normal & good & exc. & good \\
\hline
\end{tabular}


TABLE: No. 2

Circumtibial, subcutaneous transfer of tib. post. to insertion of tib. ant. and retrograde transfer of ext. dig. to tib. post. (Method No. 1.) Postoperative active dorsiflexion with straight knee:

\begin{tabular}{l|c|c}
\hline & Mild highstepping gait & Normal gait \\
\hline $71-80$ & nil & 5 \\
$81-90$ & 2 & 3 \\
$91-100$ & 1 & 3 \\
& & \\
\hline
\end{tabular}

Circumtibial, subcutaneous transfer of tib. post to insertion of tib. ant. and retrograde transfer of per. long. to tib. post. (Method No. 2.) Postoperative active dorsiflexion with straight knee:

\begin{tabular}{l|c|c}
\hline & Mild highstepping gait & Normal gait \\
\hline $61-70$ & nil & 1 \\
$71-80$ & nil & 6 \\
$81-90$ & 1 & 1 \\
$91-100$ & 1 & nil \\
\hline
\end{tabular}

(These figures as quoted from paper by the author which is under print by the Acta Orthopaedica Scandinavica.)

Circumtibial, subcutaneous transfer of the tib. post. to the ext. dig. long. on the dorsum of the foot. (Method No. 3.) Postoperative active dorsiflexion with straight knee:

\begin{tabular}{l|c|c}
\hline & Mild highstepping gait & Normal gait \\
\hline $71-80$ & 1 & 3 \\
$81-90$ & 2 & 6 \\
\hline
\end{tabular}

TABLE No. 3

\begin{tabular}{l|c|c|c}
\hline & Method No. 1 & Method No. 2 & Method No. 3 \\
\hline Excellent result: & 4 & 2 & 9 \\
Good result: & 7 & 6 & 3 \\
Fair result: & 3 & 2 & 0 \\
Poor result: & 0 & 0 & 0 \\
\hline
\end{tabular}

Explanation of terminology:

Excellent result: stable foot, in all respects normal function.

Good result: stable foot, in all essential respects satisfactory function. Fair result: some improvement in function, but not satisfactory.

Poor results: insignificant or no improvement. Distinctly unsatisfactory. 
$80^{\circ}$ active dorsiflexion. Even though the active dorsiflexion with straight knee will be less than with flexed knee (in this series $6^{\circ}$ ) this will still allow the foot to be carried forward with no highstepping in the gait.

Comparison with other tendon to tendon methods of tib. post. transfer: Although figures for a full comparison between the various techniques of tendon to tendon tibi. post. transfer are not available, it is considered of some interest to compare the results of the 3 mentioned techniques. In Table No. 2 will be found the angle of active dorsiflexion achieved postoperatively with straight knee at the various methods. The figures tend to indicate slightly better results from the methods introduced here. In Table No. 3 will be found a comparison between the final overall result in the three methods. The assessments have not been done by the same person in all the cases, and some discrepancy may be expected. Still the figures do indicate some superiority of the method introduced here.

\section{Conclusion}

A simple and quick technique of transfer of the tibialis posterior tendon for the correction foot drop is presented. It is offered as a valuable alternative to other, already described methods.

\section{Acknowledgements}

The author wishes to express his gratitude to the staff members of Santipara Leprosy Colony, notably Dr. P. Murmu, resident medical officer, and Miss Lucille Frickson, physiotherapist, to the staff members of Sevapur Hospital, and to all the patients whose cheerful cooperation has been of immense value in this study.

\section{References}

Andersen, Johs G. Neurological Patterns in Leprosy, Journal of the Christian Medical Association of India, May, 1961.

Andersen, Johs G. Foot Drop in Leprosy and its Surgical Correction, $A$ cra Scand. Orth., XXX111, 2, 151-171.

Fritschi, E. P. and Brand, P. W. The Place of Reconstructive Surgery in the Prevention of Foot Ulceration in Leprosy, Int. J. of Lepr., 25, 1, 1-8.

Gunn, D. R., and Molesworth, D. B. The Use of the Tibialis Posterior as a Desiflexor, J. Bone and Joint Sirg., 39B, 674-678.

Hodges, W. A. The Treatment of Deformities of the Foot in Leprosy, East African Med. J., 33, 302-303.

Selvapandian and Brand, P. W., Transfer of the Tibialis Posterior in Foot Drop Deformities, Ind. J. of Surg., XXI, 2, 151-160.

Thangaraj, R. H., Personal Communication, 1959. 